
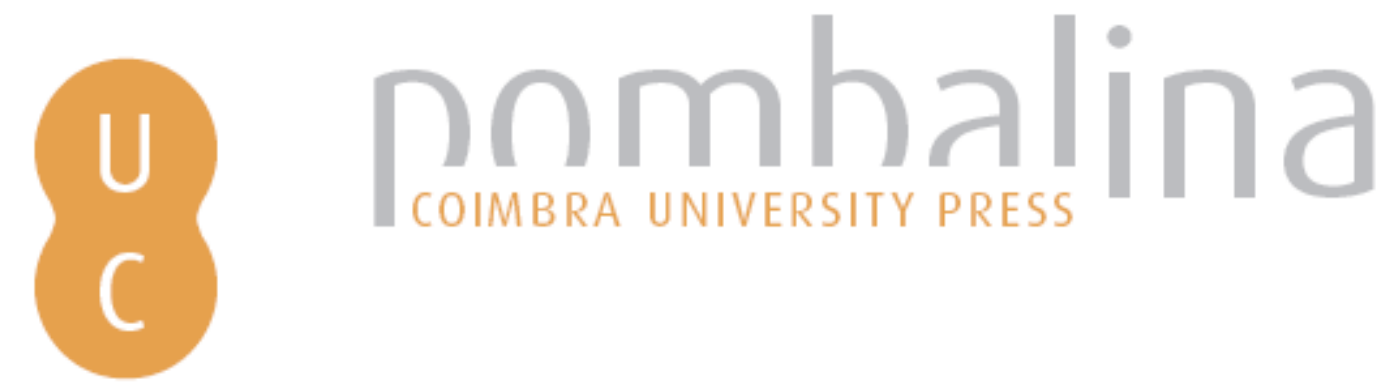

Idades químicas U-Th-Pb de monazitas de placeres marinhos de Buena (litoral norte do Rio de Janeiro, Brasil) por microssonda eletrónica: implicações geológicas

Autor(es): $\quad$ Oliveira, E. K.; Chaves, A. O.

Publicado por: Imprensa da Universidade de Coimbra

URL

persistente: URI:http://hdl.handle.net/10316.2/31462

DOI: DOI:http://dx.doi.org/10.14195/978-989-26-0534-0_34

Accessed : $\quad$ 26-Apr-2023 10:42:29

A navegação consulta e descarregamento dos títulos inseridos nas Bibliotecas Digitais UC Digitalis, UC Pombalina e UC Impactum, pressupõem a aceitação plena e sem reservas dos Termos e Condições de Uso destas Bibliotecas Digitais, disponíveis em https://digitalis.uc.pt/pt-pt/termos.

Conforme exposto nos referidos Termos e Condições de Uso, o descarregamento de títulos de acesso restrito requer uma licença válida de autorização devendo o utilizador aceder ao(s) documento(s) a partir de um endereço de IP da instituição detentora da supramencionada licença.

Ao utilizador é apenas permitido o descarregamento para uso pessoal, pelo que o emprego do(s) título(s) descarregado(s) para outro fim, designadamente comercial, carece de autorização do respetivo autor ou editor da obra.

Na medida em que todas as obras da UC Digitalis se encontram protegidas pelo Código do Direito de Autor e Direitos Conexos e demais legislação aplicável, toda a cópia, parcial ou total, deste documento, nos casos em que é legalmente admitida, deverá conter ou fazer-se acompanhar por este aviso.

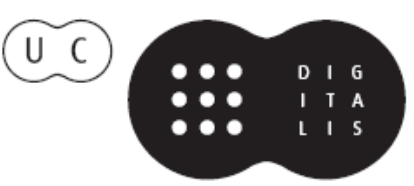





\title{
IDADES QUÍMICAS U-TH-PB DE MONAZITAS DE PLACERES MARINHOS DE BUENA (LITORAL NORTE DO RIO DE JANEIRO, BRASIL) POR MICROSSONDA ELETRÔNICA: IMPLICAÇÓES GEOLÓGICAS
}

\author{
ELECTRON MICROPROBE U-TH-PB CHEMICAL DATING \\ OF MONAZITES FROM MARINE PLACERS OF BUENA \\ (RIO DE JANEIRO NORTHERN COAST, BRAZIL): \\ GEOLOGICAL IMPLICATIONS
}

\begin{abstract}
Resumo - Dados analíticos U-Th-Pb obtidos em microssonda eletrônica permitiram calcular idades químicas (não isotópicas) em grãos composicionalmente homogêneos e heterogêneos de monazita de placeres marinhos de Buena (litoral norte do Estado do Rio de Janeiro, Brasil), utilizando-se os softwares EPMA dating e ISOPLOT. As observaçóes aqui apresentadas estão baseadas na premissa de que não existe ${ }^{204} \mathrm{~Pb}$ (não radiogênico) $\mathrm{e}$ que não houve interferência do ítrio nas raias de chumbo nos grãos de monazitas analisados. Embora os dados obtidos sejam ainda preliminares, ao se comparar as idades médias calculadas com as informaçóes do mapa da compartimentação tectônica da região sudeste brasileira levantaram-se as seguintes hipóteses: a) proveniência de um dos grãos com 950 Ma a partir do Domínio Cambuci (CA), b) proveniência dos grãos com idade entre 800 e $840 \mathrm{Ma}$ a partir de litotipos da Klippe de Italva (IT) e c) proveniência dos grãos com idades entre 765 e $780 \mathrm{Ma}$ a partir de rochas do Arco Rio Negro.
\end{abstract}

Palavras-chave - Monazita; Placeres marinhos; Rio de Janeiro; Idades químicas U-Th-Pb; Microssonda eletrônica; Proveniência mineral

Abstract - Analysis of U-Th-Pb carried out by using an electron microprobe allowed to calculate chemical ages (non isotopic) of compositionally homogeneous and heterogeneous grains of monazite from marine placers of Buena (north coast of State of Rio de Janeiro, Brazil), supported on EPMA dating and ISOPLOT softwares. The observations presented here are

1 Centro de Desenvolv. da Tecnologia Nuclear-CDTN/CNEN, Belo Horizonte, Brasil; eko@cdtn.br.

2 Dept. Geologia, Univ. Federal de Minas Gerais - UFMG, Belo Horizonte, Brasil; alochaves@yahoo.com.br. 
based on the assumption that there is no ${ }^{204} \mathrm{~Pb}$ (non radiogenic) in the monazite grains and no interference of yttrium on the lead lines of such grains. Although data obtained are still preliminary, comparing mean ages with information from the tectonic map of southeast Brazil, some

hypothesis arise: a) provenance of one 950Ma grain from Cambuci Domain, b) provenance of 800-840 Ma grains from lithologies of the Italva Klippe, and c) provenance of 765-780 Ma grains from rocks of the Rio Negro Arc.

Keywords - Monazite; Marine placers; Rio de Janeiro; U-Th-Pb chemical ages; Electron microprobe; Mineral provenance

\section{1 - Introduçáo}

A monazita, um fosfato rico em elementos de terras raras, é uma fase mineral acessória, comumente disseminada em diversos tipos litológicos (ígneos, metamórficos e sedimentares). Uma vez que este mineral contém quantidades significativas de Th e U, além de incorporar pouco ou nenhum Pb comum durante sua cristalização (PARRISH, 1990), a quantificaçáo precisa por microssonda eletrônica desses elementos actinídeos e do $\mathrm{Pb}$ radiogênico deles derivado pode ser usada para obter informaçôes cronológicas (MONTEL et al., 1996; WILLIAMS \& JERCINOVIC, 2002).

As transformaçóes ocorridas ao longo da história geológica de uma rocha podem ficar registradas no zoneamento composicional dos seus minerais. Este zoneamento é uma das feiçôes típicas encontradas em cristais de monazita (WILLIAMS et al., 2007), percebido nas imagens de elétrons retroespalhados obtidas através da microssonda.

O objetivo deste trabalho é determinar, com o apoio da microssonda eletrônica e sua elevada resolução analítica espacial, as idades U-Th-Pb dos grãos quimicamente homogêneos (monodomínio) e heterogêneos (subdomínios) de monazita dos placeres marinhos de Buena (Rio de Janeiro, Brasil), de modo a se caracterizar a proveniência (possíveis áreas fontes) desses grãos e os eventos geológicos guardados por este mineral.

\section{2 - Enquadramento geológico}

A região de Buena, área onde as monazitas foram extraídas, está localizada na porção norte do Estado do Rio de Janeiro (Brasil), geologicamente pertencente à Província Tectônica Mantiqueira. As unidades litológicas da região noroeste do Estado do Rio de Janeiro estão situadas no segmento setentrional da Faixa Ribeira (Fig. 1).

A compartimentação tectônica da Faixa Ribeira, estabelecida no seu setor central, compreende quatro terrenos tectono-estratigráficos: Ocidental, Oriental, Paraíba do Sul/ Embú e Cabo Frio. Os dois primeiros terrenos são separados por uma zona de cisalhamento complexamente redobrada (Limite Tectônico Central - LTC), com mergulhos subverticais a moderados para NW na porção centro-sul fluminense, e mergulhos para SE na porção noroeste fluminense e sul capixaba. O limite basal dos terrenos Cabo Frio e Paraíba do Sul/ Embú está representado por uma zona de cisalhamento de baixo ângulo, com mergulhos para SE e NW. Os três primeiros terrenos foram amalgamados entre $c a$. 600 e $570 \mathrm{Ma}$, enquanto que Terreno Cabo Frio foi acrescionado ao final da colagem orogênica, em $c a$. 
530-510 Ma. Estes terrenos representariam paleoplacas convergentes durante a formação do supercontinente Gondwana na transição Neoproterozóico/Cambriano. O Terreno Ocidental corresponderia à paleoplaca inferior (Placa Sanfranciscana), e o Terreno Oriental à placa superior, na qual se instalou o arco magmático responsável pela colisão Arco/Continente. Para leste, por trás do Terreno Oriental, o fechamento do espaço back-arc resultou na colisão com a paleoplaca do Terreno Cabo Frio. O Terreno Ocidental é representado pelo Domínio Tectônico Juiz de Fora, que integra rochas paleoproterozoicas do Complexo Juiz de Fora e uma sequência metassedimentar neoproterozoica conhecida como Megasseqüência Andrelândia. O Terreno Paraíba do Sul aflora como uma klippe sinformal complexamente dobrada sobre o Terreno Ocidental. É constituído por ortognaisses paleoproterozoicos do Complexo Quirino e por um conjunto metassedimentar rico em intercalações de mármores dolomíticos e de idade ainda incerta, denominado de Complexo Paraíba do Sul. O Terreno Oriental, que contem as rochas geradas em ambientes de arco magmático e metassedimentos neoproterozoicos, foi subdividido na regiáo noroeste fluminense em três domínios estruturais distintos: a) o Domínio Cambuci, em posição basal, compreende uma sequência metavulcano-sedimentar com lentes de mármore e ortognaisses calcioalcalinos com ambiência tectônica de arco magmático; b) o Domínio Costeiro é constituído por metassedimentos pelíticos em fácies granulito a anfibolito alto, com intercalaçóes de quartzitos impuros intrudidos por ortognaisses e metagabros do Arco Magmático Rio Negro (ca. 790 a $620 \mathrm{Ma}$ ); c) a Klippe de Italva aflora sobre o Domínio Costeiro e compreende um conjunto metavulcanossedimentar com mármores calcíticos, anfibolitos ( $c$. $840 \mathrm{Ma}$ ) e paragnaisses com provável contribuição vulcânica. O Terreno Cabo Frio não aflora na região noroeste fluminense, sendo limitado por uma falha rúptil de direção NWW-SEE (TUPINAMBÁ et al., 2007).

A área dos placeres, na regiáo de Buena, caracteriza-se pela presença de corpos arenosos, marinhos, classificados mais especificamente como cordóes litorâneos ou cristas praiais (SUGUIO, 1998) paralelos à linha de praia, ora afastando-se, ora aproximando-se da linha de praia atual (MARTIM et al., 1997). Estes cordôes abrigam minerais pesados, dentre os quais encontram-se os grãos de monazita deste estudo. A regiáo de Buena encontra-se próxima da foz do Rio Itabapoana, rio que atravessa as litologias pertencentes ao Domínio Cambuci (CA) e Klippe Italva (IT).

\section{3 - Metodologia}

Os grãos de monazita aqui investigados foram coletados em um concentrado final proveniente da região de Buena, em jazidas de placeres marinhos explotadas pela INB (Indústrias Nucleares do Brasil). Esses grãos foram montados em lâminas delgadas polidas e seçóes polidas que possibilitaram as microanálises, com determinações quantitativas simultâneas de Th, $\mathrm{U}$ e $\mathrm{Pb}$ (total), executadas em microssonda eletrônica (marca JEOL - modelo JXA-8900 - instalada na Universidade Federal de Minas Gerais), através do método de espectrometria por dispersão de comprimento de onda (WDS).

Para executar as microanálises dos grãos de monazita, conforme o procedimento de VLACH (2010), foram estabelecidas as condiçôes instrumentais de 300nA de intensidade da corrente de feixe, $15 \mathrm{kV}$ de tensão de aceleração e $1 \mu \mathrm{m}$ para o diâmetro do feixe. Os padrôes analíticos utilizados foram $\mathrm{UO}_{2}(\mathrm{U}), \mathrm{ThSiO}_{4}(\mathrm{Th})$ e $\mathrm{PbCrO}_{4}(\mathrm{~Pb})$. 


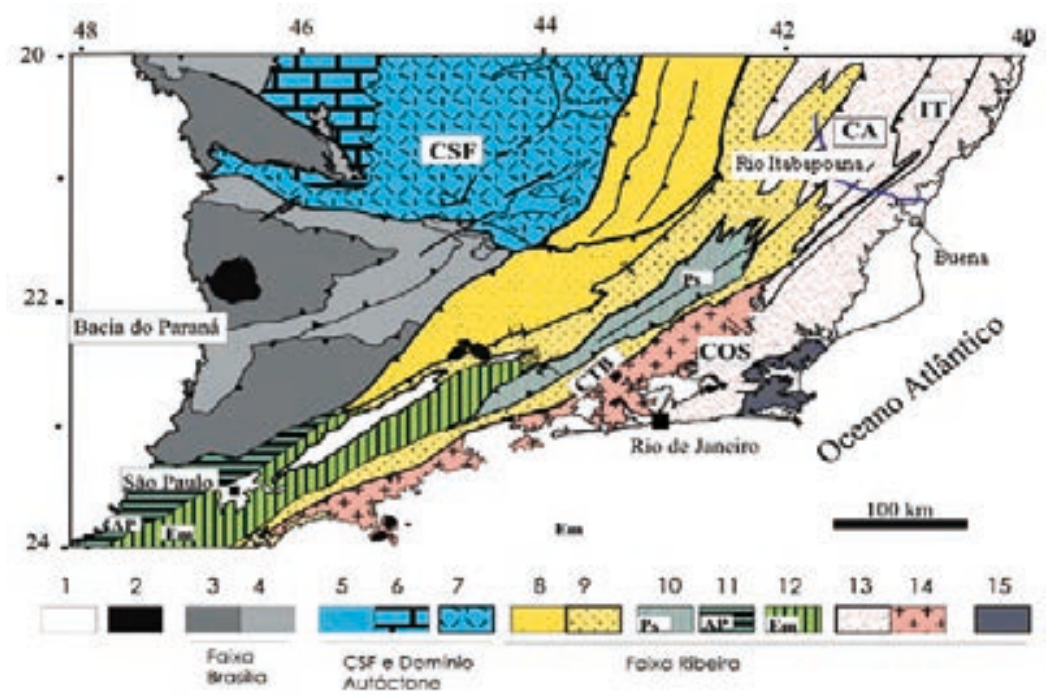

Legenda: 1 - Coberturas Fanerozóicas; 2 - Rochas Alcalinas do K/Eoceno; 3 a 4: Faixa Brasília: 3 - Domínio Externo, 4 - Domínio Interno; 5 a 7: Craton do São Francisco e Domínio autóctone: 5 - Megasseqüência Andrelândia autóctone, 6 - Supergrupo Bambuí, 7 - Embasamento cratônico; 8 a 15: terrenos da Faixa Ribeira: 8 - Terreno Ocidental/Domínio Andrelândia, 9 - Terreno Ocidental/ Domínio Juiz de Fora, 10 - Terreno Paraíba do Sul, 11 - Terreno Apiaí, 12 - Terreno Embú, 13 - Terreno Oriental: CA - Domínio Cambuci, IT - Klippe Italva, COS - Domínio Costeiro, 14 - Terreno Oriental/ Arco magmático Rio Negro, 15 - Terreno Cabo Frio.

Fig. 1- Mapa da compartimentaçấo tectônica da região sudeste brasileira (TUPINAMBÁ et al, 2007).

\section{4 - Resultados}

Como relação aos aspectos macroscópicos, a monazita apresenta grãos arredondados, turvos, cor amarelo claro, exibindo marcas na superfície provavelmente devidas ao mecanismo de abrasão das ondas do oceano.

A composição química de 12 dos grãos de monazita, analisados pela microssonda eletrônica (tabela 1), incluíram valores de U-Th-Pb, que serviram de base para os cálculos das idades químicas, utilizando o software EPMA dating (POMMIER et al., 2004) e também para as idades por média ponderada calculadas pelo software ISOPLOT (LUDWIG, 2003) com intervalo de confiança de 95\%. As idades químicas U-Th-Pb calculadas encontram-se na tabela 2 .

A maioria dos grãos analisados através da microssonda eletrônica exibe uma distribuição homogênea do tom de cinza, enquanto dois grãos (G6 e SP-G1) apresentam tons de cinza contrastantes formando subdomínios heterogêneos e irregulares (Fig. 2). Os dois únicos grãos heterogêneos G6 e SP-G1 exibem a mesma idade média correspondendo a 779ะ14 Ma.

Considerando grãos homogêneos e heterogêneos, a distribuição de suas idades médias abrange, preferencialmente, dois intervalos: 765 a $779 \mathrm{Ma}$ (5 grãos) e 801 a 839 Ma (6 grãos). Um único grão G10 (949 $\pm 52 \mathrm{Ma})$ demonstrou uma idade mais elevada que todos os demais. 


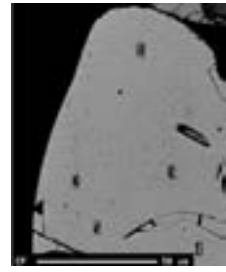

a) G7 - grão homogêneo

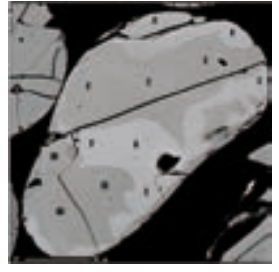

b) G6 - grão heterogêneo

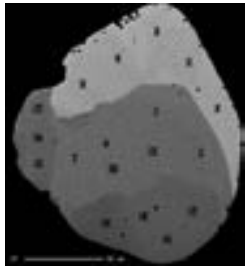

c) SP-G1 - grão heterogêneo

Fig. 2 - Imagens por elétrons retroespalhados destacam os tons de cinza. (a) Interior de um grão homogêneo (monodomínio). (b e c) Grãos heterogêneos (com subdomínios composicionais).

As fraturas apresentadas pelos grãos em (a) e (b) não são originais, mas produzidas pelo processo de polimento dos grãos necessário para as microanálises.

\section{5 - Discussôes e conclusôes}

A variação das idades médias nos grãos de monazita investigados abrange um intervalo bastante amplo $(765 \pm 32 \mathrm{Ma}$ até $949 \pm 52 \mathrm{Ma})$, podendo indicar proveniências bastante diversas para esses grãos.

Quando as idades médias calculadas nessas análises são comparadas às informaçôes do mapa da compartimentação tectônica da região sudeste brasileira (Fig. 1), levantam-se as seguintes hipóteses: a) proveniência do grão G10 (950 Ma) a partir do Domínio Cambuci (CA), que corresponde à porção basal do Terreno Oriental da Faixa Ribeira, b) proveniência dos gráos com idade entre 800 e $840 \mathrm{Ma}$ a partir de litotipos da Klippe de Italva (IT) e c) proveniência dos grãos com idades entre 765 e $780 \mathrm{Ma}$ a partir de rochas do Arco Rio Negro, ainda que atualmente náo drenado pelo Rio Itabapoana, mas drenado por outros rios próximos a Buena.

Nos grãos heterogêneos G6 e SP-G1, provavelmente também de origem a partir do Arco Rio Negro, conforme as áreas onde existe uma distribuição irregular de subdomínios com diferentes tons de cinza (claro, médio e escuro, Fig. 2), observam-se diferentes idades médias,

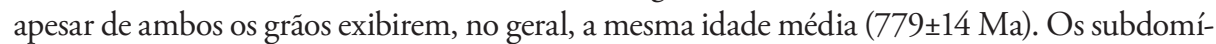
nios cinza claro, mais comuns nas bordas dos grãos G6 e SP-G1, apresentam idade menor (G6 $=771 \pm 27 \mathrm{Ma}$; SP-G1 = $777 \pm \mathrm{n} 25 \mathrm{Ma}$ ) em relação aos subdomínios cinza médio que ocorrem nas porçôes centrais dos grãos (G6 = $782 \pm 16 \mathrm{Ma}$; SP-G1 = $782 \pm 25 \mathrm{Ma})$. O subdomínio cinza escuro, que ocorre apenas nas bordas do gráo SP-G1, apresenta uma idade ainda mais nova que a do subdomínio cinza claro, também de borda neste grão (763 $\pm 25 \mathrm{Ma})$. Estas observaçôes sugerem que o subdomínio interno cinza médio guarde o evento inicial de cristalização destas monazitas heterogêneas por volta de $782 \mathrm{Ma}$, enquanto que os subdomínios externos cinza claro e escuro guardem o evento final da cristalização e possivelmente um evento de recristalização, cerca, respetivamente, $10 \mathrm{Ma}$ e $20 \mathrm{Ma}$ posteriores à cristalização inicial. O teor incorporado de $\mathrm{ThO}_{2}$ foi menor no início da cristalização da monazita SP-G1 (7,8\%, no subdomínio cinza médio), maior na fase final de cristalização (11,1\% no subdomínios cinza claro) e ainda menor (7,31\% no escuro) numa possível recristalização tardia.

Cabe finalmente destacar que, caso haja ${ }^{204} \mathrm{~Pb}$ (não radiogênico) ou tenha ocorrido possíveis interferências do ítrio nas raias de chumbo dos grãos de monazitas analisados, 
as idades, preliminarmente obtidas, estariam superestimadas e deveriam ser mais jovens. Portanto, análises isotópicas U-Pb por LA-ICP-MS atualmente em curso ajudarão na definição das idades dos respectivos grãos e das suas proveniências geológicas.

Tabela 1 - Composiçôes químicas das monazitas de Buena

\begin{tabular}{|c|c|c|c|c|c|c|c|c|c|c|c|c|c|c|c|}
\hline pot & $\mathrm{O} 2$ & $\mathrm{aO}$ & $\mathrm{O} 2$ & 2 & $\mathrm{O} 3$ & Y & $\mathrm{O}$ & 3 & $\mathrm{P} 2 \mathrm{O} 5$ & 3 & $\mathrm{r}$ & $\ln 20$ & 3 & 3 & Totol \\
\hline & 6 & 5 & ,41 & 9,24 & o & 0,13 & 0,30 & 28,97 & 4 & 2, & 10,90 & 1,21 & 5 & 8 & . \\
\hline & 14 & 56 & . & 9,66 & 6,38 & 0,08 & 0,33 & 30,09 & 5,30 & 3,08 & 9,49 & 1,11 & 0,69 & 21 & 8,48 \\
\hline 1.4 & 13 & 61 & 23 & 9,48 & 6,52 & 0,08 & 0,33 & 29,36 & 24,61 & 2,93 & 10,25 & 1,15 & 0,68 & 0,25 & 97,61 \\
\hline 2.2 & 15 & 07 & 22 & 5,87 & 4,18 & 0,06 & 0,23 & 30,78 & 29,47 & 3,12 & 12,68 & 2,27 & ,43 & 24 & 01,7 \\
\hline .3 & 23 & 99 & 31 & 85 &, 32 & 0 , & 0,22 & & 27,26 & 3,06 & & 4 & & 31 & \\
\hline 2.4 & 26 & 99 &, 22 & 5,74 & 4,64 & 0,04 & 0,22 & 30,29 & 28,15 & 3,25 & 11,72 & 2,29 & 1,45 &, 36 & 99,61 \\
\hline 2.5 & 10 & 02 & 28 & 5,73 & 3,93 & 0,07 & 0,22 & 31,45 & 28,30 & 3,25 & 12,56 & 2,26 & 1,46 & ,28 & 100,9 \\
\hline .6 & 26 & 01 & 28 & .77 & & 0 & 0,22 & 13 & 28,93 & 3,09 & & 2,29 & & 22 & 2, \\
\hline 2 & 03 & 1,08 & 18 & 5,88 & 4,45 & 0,32 & 0,23 & 28,93 & 30,00 & 3,18 & 10,86 & 2,07 & 1,22 & 46 & 8,87 \\
\hline 3.3 & 0,10 & 1,09 & 23 & 6,32 & 14,39 & 0,21 & 0,22 & 27,86 & 28,89 & 3,08 & 11,62 & 1,83 & 1,11 &, 32 & 97,27 \\
\hline .4 & 13 & 17 & 20 & 6,03 & 4,19 & 0,22 & 0,22 & 28,87 & 28,59 & 3,08 & & 1,94 & 13 & 33 & 7,77 \\
\hline .3 & .07 & 0,90 & 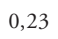 & 4,73 & 5,52 & 0,14 & 0,18 & 61 & 28,93 & 3,17 & 0 & 1,99 & 1,27 & 38 & 98,92 \\
\hline 4.4 &, 25 & 0,84 &, 23 & 4,86 & 5,10 & 0,08 & 0,20 & 30,48 & 27,24 & 3,19 & 10,96 & 2,12 & 1,30 &, 41 & 97,2 \\
\hline 4.5 & 20 & 0,93 & 29 & 5,77 & 4,73 & 0,01 & 0,22 & 30,75 & 27,90 & 3,12 & ,84 & 2,03 & 0,91 & 06 & 97,76 \\
\hline & 00 & 0,68 & & 5,93 & 80 & 0, & 0,21 & 27 & 26,39 & 3,10 & & 1,40 & & & 97,66 \\
\hline 4.7 & 11 & 0 & 2 & 5, & 15,64 & 0 & 0,19 & 3 & 2 & 3. & & 1 & 3 & & 8,77 \\
\hline 4.8 & 0,28 & 0,89 & 23 & 4,86 & 20 & 0,10 & 0,20 & 29,88 & 28,75 & 3,46 & 11,04 & 2,15 & 1,44 &, 34 & 98,81 \\
\hline .2 & 00 & 0 & 97 & 7,03 & 9,97 & 0,0 & 0,25 & 31,98 & 28,55 & 2,91 & 8, & 0,97 & 0,44 & 6 & 102,5 \\
\hline & 0 & & & 7 & & & & & & & & & & & 123 \\
\hline .4 &, 10 & 0,62 & 91 & 7,29 & 31 & 0,03 & 0,24 & 32,29 & 28,46 & 2,97 & 9,20 & 1,17 & 0,47 & 0,11 & 102 , \\
\hline .5 & 0,11 & 0,52 & 44 & 8,26 & 19,97 & 0,0 & 0,27 & 32,06 & 27,32 & 2,48 & 8,65 & 0,97 & 0,41 & 06 & 2,5 \\
\hline & 00 & & & & & & & & & & & & & & \\
\hline 5.2 & 09 & 0,97 & 09 & 48 &, 54 & 0 , & 33 & 30,40 & 27,48 & 3,33 & 13,26 & 2,17 & 0,97 & 0,18 & 102 \\
\hline 6.3 &, 10 & 1,50 & 37 & 7,97 & 11,01 & 0,12 & 0,28 & 28,59 & 29,52 & 3,40 & 13,67 & 2,56 & 1,41 & 0,39 & 100,8 \\
\hline .7 & & 1,52 & & & & & & & & & & & & & 1,4 \\
\hline 5 & 0,11 & 1,49 & 0,40 & 8 & 09 & 0 & 8 & 77 & 30,30 & 3,43 & & 2,59 & 1,40 & 8 & 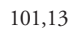 \\
\hline 6 & 10 & 0,98 & 17 & 9,74 & 2,41 & 0,05 & 0,32 & 28,35 & 28,34 & 3,31 & 12,81 & 2,01 & 0,96 & 0,22 & 100,7 \\
\hline 6.7 & 0,10 & 0,94 & 1 & 9,73 & 2,33 & 0,07 & 0,32 & 28,53 & 28,22 & 3,43 & 12,56 & 2,00 & 0,95 & 0,24 & $100, C$ \\
\hline & 0,08 & & & 6,6 & & & & 30, & 29,39 & 3,42 & & 2,5 & 1 & 4 & \\
\hline 5.10 & ,09 & 1,41 & 35 & 7,20 & 1,95 & 0,18 & 0,24 & 30,26 & 29,42 & 3,51 & 14,06 & 2,51 & 1,40 & 0,35 & 102,9 \\
\hline 6.11 & 0,06 & 1,68 & 0,4 & 8,21 & 1,46 & 0,22 & 0,29 & 29,49 & 28,77 & 3,53 & 13,80 & 2,47 & 1,59 & 32 & 2,3 \\
\hline 0.12 & 10 & 61 & 4 & 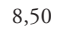 &, 04 & & 0,29 & 29,76 & 28,25 & 3,47 & & 2,57 & 4 & 32 & \\
\hline & 0,33 & 1,4 & 0,60 & 9,9 & 302 & & & 30,88 & 27,25 & 3,51 & & 2,02 & 0,61 & 12 & 102 \\
\hline 6.14 & 0,44 & 1,37 & 0,64 & 9,20 & 13,86 & 0,00 & 0,37 & 31,89 & 26,96 & 3,43 & 11,53 & 1,87 & 0,61 & 0,05 & 02 \\
\hline 0.1 & 46 & 1,4 & 0,55 & 9,1 & , & 0,0 & & & 26,84 & 3,36 & 12,46 & 1,89 & 0,65 & 16 & 102, \\
\hline &, 51 & 1,40 & & 9,5 & & & & & 25,84 & 3,19 & & 1,94 & 0,68 & 5 & 02 , \\
\hline G6.17 & 0,51 & 1,36 & 0,56 & 9,19 & 13,56 & 0,01 & 0,37 & 31,61 & 26,50 & 3,23 & 12,45 & 1,81 & 0,69 & 0,12 & 01 \\
\hline Go.18 &, 50 & 1,53 & 0,60 & 9,83 & $3, / 2$ & 0,01 & 0,39 & 30,99 & 26,39 & 3,40 & 12,92 & 1,86 & 0,70 & 0,03 & 102, \\
\hline & 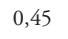 & 1,43 & 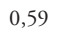 & 8,9 & 13,61 & 0,0 & 0,36 & 30,23 & 27,87 & 3,38 & 12,37 & 1,74 & 0,73 & 0,22 & 01,9 \\
\hline G7.8 & 0,31 & 1,31 & 0,53 & 8,96 & 412 & 0,01 & 0,36 & 31,32 & 26,71 & 3,02 & 12,05 & 1,78 & 0,65 &, 07 & 01 \\
\hline G7.9 & 0,28 & 1,43 & 0,54 & 8,93 & 12,80 & 0,00 & 0,37 & 29,78 & 27,28 & 3,02 & 11,76 & 1,82 & 0,54 & 0,09 & 98,6 \\
\hline & ,00 & 0,36 & 1,23 & 6,5 & 16,64 & 0,30 & 0,24 & 32,80 & 28,47 & 2,99 & 9,90 & 1,32 & 0,63 & 0,29 & 101,7 \\
\hline G8.2 & 0,09 & 0,39 & 1,14 & 6,92 & 17,56 & 0,13 & 0,25 & 34,21 & 28,40 & 2,65 & 10,04 & 1,01 & 0,66 & 0,30 & 103,7 \\
\hline 8.3 & 0,10 & 0,40 & ,14 & 6,91 & 17,25 & 0,13 & 0,24 & 34,43 & 28,58 & 2,88 & 10,02 & 1,24 & 0,44 & 0,19 & 103,9 \\
\hline
\end{tabular}


Tabela 1 - Continuação.

\begin{tabular}{|c|c|c|c|c|c|c|c|c|c|c|c|c|c|c|c|}
\hline 8.4 & 0,09 & 0,45 & 1,14 & 7,05 & 17,77 & 0,11 & 0,25 & 34,26 & 28,25 & 3,15 & 10,10 & 14 & 0,51 & 0,12 & \\
\hline G9.1 & 0,03 & 0,59 & 1,15 & 7,77 & 14,41 & 0,36 & 0,29 & 29,84 & 26,82 & 2,86 & 10,97 & 1,55 & 1,05 & 0,37 & 98,07 \\
\hline 9.2 & 0,18 &, 58 & ,08 & 7,53 & 15,08 & 0,27 & 0,27 & 30,29 & 26,97 & 3,09 & 10,94 & 1,68 & 1,05 & 0,35 & 99,35 \\
\hline 9.3 & 0,18 & 0,52 & 10 & 7,63 & 14,58 & 0,29 & 0,28 & 30,40 & 27,02 & 3,02 & 10,58 & 1,80 & 1,03 & 0,46 & 98,88 \\
\hline 9.4 & 0,18 & 56 & 6 & 7,74 & 14,71 & 0,33 & 0,29 & 77 & 27,16 & 14 & 10,46 & 1,72 & 10 & 37 &, 68 \\
\hline 9.5 & 0,18 & 58 & 19 & 7,64 &, 34 & 0,33 & 0,28 & 29,91 & 26,73 & 2,80 & 10,47 & 1,76 & 1,21 & 0,56 & 97,98 \\
\hline G10.1 & 0,32 & 0,41 & 0,42 & 3,14 & 14,02 & 0,60 & 0,17 & 29,83 & 29,34 & 3,09 & 12,21 & 2,57 & 1,74 & 0,90 & 98,76 \\
\hline 10.2 & 0,49 & 0,41 & 0,50 & 3,38 & 12,92 & 0,77 & 0,21 & 29,62 & 30,24 & 3,29 & 12,97 & 2,57 & 1,98 & 0,94 & 00,29 \\
\hline 10.3 & 0,34 & 39 & 44 & 2,66 & 4,39 & 0,67 & 0,15 & 31,51 & 30,39 & 3,22 & 12,36 & 2,39 & 1,76 & 0,89 & \\
\hline G10.4 & 0,32 & 0,39 & 0,42 & 2,37 & 14,44 & 0,70 & 0,14 & 31,42 & 30,48 & 3,15 & 13,01 & 2,50 & 1,73 & 0,86 & 101,94 \\
\hline G10.5 & 0,33 & 0,42 & 0,43 & 2,44 & 14,02 & 0,66 & 0,15 & 30,99 & 30,04 & 3,32 & 12,64 & 2,52 & 1,62 & 0,86 & 100,42 \\
\hline 11.2 & 0,12 & 0,80 & 0,31 & 5,44 & 14,58 & 0,02 & 0,19 & 32,37 & 25,48 & 3,23 & 12,38 & 1,82 & 0,67 & 0,07 & 97,47 \\
\hline 11.3 & 0,11 & 0,78 & 0,31 & 5,39 & 14,53 & 0,01 & 0,19 & 32,03 & 26,15 & 3,42 & 11,64 & 1,88 & 0,61 & 0,09 & 97,11 \\
\hline 111.4 & 0,12 & 0,69 & 0,28 & 5,04 & 14,72 & 0,00 & 0,18 & 31,97 & 27,77 & 3,31 & 11,41 & 1,73 & 0,58 & 0,06 & 97,84 \\
\hline SP-G1.2 & 0,20 & 0,58 & 1,83 & 10,87 & 17,45 & 0,07 & 0,39 & 30,43 & 26,32 & 2,70 & 8,39 & 0,89 & 0,35 & 0,00 & 100,46 \\
\hline P-G1.3 & 0,21 & 0,63 & 1,90 & 11,34 & 16,22 & 0,08 & 0,41 & 31,07 & 26,09 & 2,87 & 8,79 & 0,98 & 0,32 & 0,11 & 101,03 \\
\hline P-G1.4 & 0,22 & 0,63 & 1,80 & 11,07 & 17,35 & 0,08 & 0,38 & 30,96 & 26,25 & 2,56 & 8,88 & 0,99 & 0,42 & 0,11 & 101,68 \\
\hline P-G1.5 & 0,21 & 0,60 & 1,85 & 11,29 & 17,32 & 0,05 & 0,40 & 30,52 & 26,45 & 2,62 & 8,61 & 0,96 & 0,31 & 0,19 & 101,38 \\
\hline SP-G1.6 & 0,14 & 0,64 & 1,03 & 7,83 & 17,70 & 0,06 & 0,29 & 33,28 & 27,78 & 2,77 & 9,34 & 0,97 & 0,39 & 0,07 & 102,27 \\
\hline ?-G1.7 & 0,14 & 0,77 & 1,05 & 7,76 & 17,55 & 0,05 & 0,27 & 32,99 & 27,74 & 2,95 & 9,64 & 1,05 & 0,42 & 0,10 & 102,46 \\
\hline SP-G1.8 & 0,14 & 0,61 & 1,02 & 7,75 & 17,38 & 0,04 & 0,27 & 32,64 & 27,63 & 3,03 & 9,17 & 1,04 & 0,38 & 0,08 & 101,19 \\
\hline SP-G1.9 & 0,13 & 0,67 & 1,01 & 7,58 & 17,84 & 0,05 & 0,27 & 32,64 & 27,89 & 2,70 & 9,25 & 0,95 & 0,47 & 0,00 & 101,43 \\
\hline SP-G1.10 & 0,12 & 0,60 & 1,05 & 7,81 & 17,82 & 0,04 & 0,28 & 32,58 & 28,08 & 2,84 & 8,62 & 1,05 & 0,50 & 0,08 & 101,45 \\
\hline -G1.11 & 0,09 & 0,68 & 1,0 & 7,80 & 16,74 & 0,07 & 0,28 & 33,13 & 29,29 & 2,83 & 8,31 & 1,02 & 0,49 & 0,14 & 101,94 \\
\hline SP-G1.12 & 0,05 & 0,63 & 0,91 & 5,97 & 19,76 & 0,04 & 0,20 & 33,49 & 29,15 & 2,98 & 8,46 & 0,82 & 0,35 & 0,07 & 102,87 \\
\hline SP-G1.13 & 0,07 & 0,58 & 1,07 & 6,79 & 18,89 & 0,04 & 0,23 & 33,87 & 28,62 & 2,74 & 8,82 & 0,78 & 0,25 & 0,07 & 102,81 \\
\hline P-G1.14 & 0,07 & 0,56 & 1,07 & 6,84 & 18,44 & 0,03 & 0,23 & 33,68 & 28,60 & 2,73 & 8,97 & 0,89 & 0,38 & 0,00 & 102,47 \\
\hline SP-G1.15 & 0,06 & 0,57 & 1,07 & 6,79 & 18,87 & 0,03 & 0,23 & 33,81 & 28,96 & 2,74 & 8,63 & 0,72 & 0,34 & 0,00 & 102,81 \\
\hline SP-G1.16 & 0,13 & 0,81 & 0,92 & 7,82 & 16,18 & 0,07 & 0,28 & 33,52 & 29,53 & 2,79 & 7,02 & 1,31 & 0,61 & 0,16 & 101,13 \\
\hline SP-G1.17 & 0,11 & 0,90 & 0,78 & 7,84 & 15,56 & 0,08 & 0,27 & 31,87 & 29,54 & 3,10 & 10,36 & 1,35 & 0,61 & 0,16 & 102,53 \\
\hline SP-G1.18 & 0,12 & 1,01 & 0,81 & 7,78 & 15,62 & 0,08 & 0,27 & 31,29 & 29,50 & 3,06 & 10,30 & 1,36 & 0,62 & 0,12 & 101,93 \\
\hline
\end{tabular}

Tabela 2 - Idade U-Th-Pb em monazita, utilizando o software EPMA dating (Pommier et al., 2004) Média ponderada calculada pelo software ISOPLOT (Ludwig, 2003) com intervalo de confiança de 95\%

\begin{tabular}{|c|c|c|c|c|c|c|c|c|c|c|c|c|}
\hline REF & $\begin{array}{l}\text { Age } \\
\text { Ma }\end{array}$ & $\begin{array}{c}\text { Erro } \\
\text { Age } \\
\mathrm{Ma}\end{array}$ & $\begin{array}{c}\mathrm{U} \\
\mathrm{ppm}\end{array}$ & $\begin{array}{c}\text { Erro } \\
\mathrm{U} \\
\mathrm{ppm}\end{array}$ & $\begin{array}{c}\text { Erro } \\
U \\
\%\end{array}$ & $\begin{array}{c}\text { Th } \\
\text { ppm }\end{array}$ & $\begin{array}{c}\text { Erro } \\
\text { Th } \\
\text { ppm }\end{array}$ & $\begin{array}{c}\text { Erro } \\
\text { Th } \\
\%\end{array}$ & $\begin{array}{c}\mathrm{Pb} \\
\mathrm{ppm}\end{array}$ & $\begin{array}{c}\text { Erro } \\
\mathrm{Pb} \\
\mathrm{ppm}\end{array}$ & $\begin{array}{c}\text { Erro } \\
\mathrm{Pb} \\
\%\end{array}$ & Domínio \\
\hline G1.2 & 751 & 59 & 494 & 150 & 30 & 81219 & 1624 & 2 & 2813 & 150 & 5 & - \\
\hline G1.3 & 756 & 56 & 1199 & 150 & 13 & 84910 & 1698 & 2 & 3036 & 150 & 5 & - \\
\hline G1.4 & 786 & 57 & 1164 & 150 & 13 & 83301 & 1666 & 2 & 3101 & 150 & 5 & - \\
\hline \multicolumn{13}{|c|}{ Mean $=765 \pm 32[4.2 \%]$. Wtd by data-pt errs only. MSWD $=0.4$, probability $=0.64$} \\
\hline G2.2 & 847 & 82 & 1278 & 150 & 12 & 51577 & 1032 & 2 & 2144 & 150 & 7 & - \\
\hline G2.3 & 785 & 77 & 2054 & 150 & 7 & 51427 & 1029 & 2 & 2070 & 150 & 7 & - \\
\hline G2.4 & 764 & 77 & 2301 & 150 & 7 & 50399 & 1008 & 2 & 2005 & 150 & 7 & - \\
\hline G2.5 & 841 & 85 & 908 & 150 & 17 & 50364 & 1007 & 2 & 2033 & 150 & 7 & - \\
\hline G2.6 & 783 & 77 & 2327 & 150 & 6 & 50724 & 1014 & 2 & 2070 & 150 & 7 & - \\
\hline \multicolumn{13}{|c|}{ Mean $=801 \pm 35[4.3 \%]$. Wtd by data-pt errs only. MSWD $=0.87$, probability $=0.48$} \\
\hline G3.2 & 878 & 88 & 247 & 150 & 61 & 51647 & 1033 & 2 & 2089 & 150 & 7 & - \\
\hline G3.3 & 783 & 78 & 899 & 150 & 17 & 55505 & 1110 & 2 & 2070 & 150 & 7 & - \\
\hline G3.4 & 791 & 80 & 1155 & 150 & 13 & 52956 & 1059 & 2 & 2033 & 150 & 7 & - \\
\hline
\end{tabular}




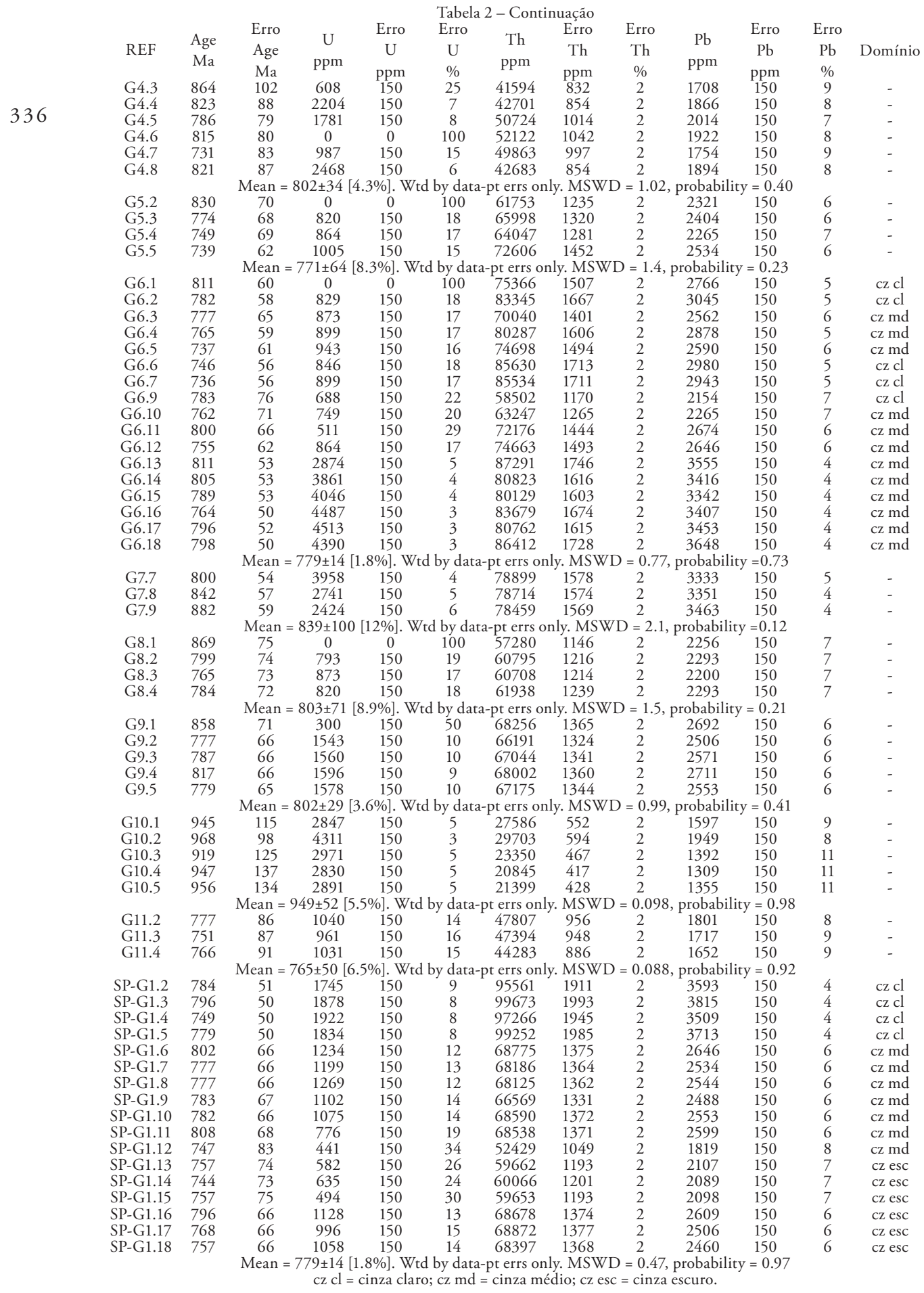


Agradecimentos - Os autores expressam profunda gratidão pelos ensinamentos durante a convivência com o prof. Dr. José Marques Correia Neves (in memoriam) que foi o orientador inicial. Agradecemos Ao Dr. Luiz Garcia pelas microanálises.

\section{Referências Bibliográficas}

INDÚSTRIAS NUCLEARES DO BRASIL (INB) - Disponível em http://www.inb.gov.br/inb/WebForms/ interna.aspx?secao_id=62 (consultado em 01.09.2011).

LUDWIG, K. R. (2003) - Isoplot/Ex 3.00: a geochronological toolkit for Microsoft Excel. Berkeley Geochronology Center. Special Publication, 4, 70 p.

MARTIN, L., SUGUIO, K., DOMINGUEZ, J. M. L. \& FLEXOR, J-M. (1997) - Geologia do quaternário costeiro do litoral norte do Rio de Janeiro e do Espírito Santo/ Louis Martin. Belo Horizonte: CPRM, 112 p.

MONTEL, J. M., FORET, S., VESCHAMBRE, M., NICOLLET, C., \& PROVOST, A. (1996) - Electron microprobe dating of monazite. Chemical Geology, 131, p. 37-53.

PARRISH, R. R. (1990) - U-Pb dating of monazite and its application to geological problems. Canadian Journal of Earth Sciences, 27, p. 1431-1450.

POMMIER, A., COCHERIE, A. \& LEGENDRE, O. (2004) - EPMA Dating: age calculation from electron probe microanalyser measurements of U-Th-Pb. BRGM, Orleans, France, 9 p.

SUGUIO, K. (1998) - Dicionário de geologia sedimentar e áreas afins, Bertrand Brasil, 1222 p.

TUPINAMBÁ, M., HEILBRON, M., DUARTE, B. P., NOGUEIRA, J. R., VALLADARES, C., ALMEIDA, J., SILVA, L. G. E., MEDEIROS, S. R., ALMEIDA, C. G., MIRANDA, A., RAGATKY, C. D., MENDES, J. \& LUDKA, I. (2007) - Geologia da Faixa Ribeira Setentrional: Estado da Arte e Conexôes com a Faixa Araçuaí. Geonomos, 15, p. 67-79.

VLACH, S. R. F. (2010) - Th-U-Pb ${ }_{T}$ dating by the Electron Probe Microanalysis, Part I. Monazite: Analytical procedures and data treatment. Geologia USP. Série Científica, 10, p. 61-85.

WILLIAMS, M. L. \& JERCINOVIC, M. J. (2002) - Microprobe monazite geochronology: putting absolute time into microstructural analysis. Journal of Structural Geology, 24, p. 1013-1028.

WILLIAMS, M. L., JERCINOVIC, M. J. \& HETHERINGTON, C. J. (2007) - Microprobe Monazite Geochronology: understanding geologic processes by integrating composition and chronology. Annual Reviews of Earth and Planetary Sciences, 35, p. 137-175. 